\title{
Characterization of the Rotor Magnetic Field in a Brushless Doubly-Fed Induction Machine
}

F. Blázquez,

\author{
C. Veganzones, D, Ramírez,
}

\author{
and C. Platero
}

\begin{abstract}
The large increase in wind generation could improve the final development of wind systems with brushless doubly-fed induction machines (BDFIM) as an alternative to the doubly-fed asynchronous machines. For this reason, a detailed study of several aspects of the BDFIM design, as well as of its rotor configuration, is absolutely essential. In this paper, the authors present an alternative formulation of the BDFIM operating principle in synchronous mode. Besides the basic equation of the machine operation, it presents as main advantage the precise characterization of all the magnetic field components in a BDFIM with idealized stator windings and an idealized rotor cage. Based on this formulation, the paper provides a standard that may be used to compare the fields created by different real BDFIMs. This standard has been validated by laboratory tests.
\end{abstract}

Index Terms-Brushless rotating machines, electromagnetic analysis, electromagnetic coupling, induction machines.

\section{INTRODUCTION}

$\mathbf{T}$ HE USE of asynchronous motors in variable-speed drives constituted an important challenge until the development of frequency converters. A few techniques were developed, however, before the industrial application of these converters. The cascade connection of slip-ring machines with a common shatt, developed by Steinmetz and Görges, was one very good alternative.

During the 20 th century, the cascade connection concept was continuously improved. The most important evolution was the development of the cascade connection concept in a single machine, called "self-cascade machine" [1], whose stator configuration was presented in [2]. The last notable enhancement was the simplified electrical rotor circuit proposed in 1970 [3], which remains to this day.

From then, the study of the self-cascade machine waned until the early 1990 s, when the possibility of using this machine as an alternative to the doubly-fed asynchronous machine (DFAM) was considered in variable-speed drives. In this way, in 1991, a mathematical model was developed for the "self-cascade machine" called "cage-rotor brushless doubly-fed machine" [4]. In 1992, the final evolution of the "self-cascade" concept, named "Brushless Doubly-Fed Machine," emerged [5]. In this paper, it is called "brushless doubly-fed induction machine" (BDFIM).

Also, in the 1990s, the use of the BDFIM in wind power generation systems was outlined in different experimental studies [6]. At the present time, the large increase in wind generation could even impel the final development of wind systems with BDFIM.

In electrical power systems with a high percentage of wind power (e.g., in Spain, it reaches 10\%), the employment of variable-speed wind turbines is essential in order to regulate the electrical energy generated. Nowadays, most variable-speed wind turbines use a DFAM because the electronic converter power requirement is lower than the electrical generator's rated power.

A hypothetical BDFIM wind generator would also use a reduced-power electronic converter, and it would also have other advantages in wind systems, e.g., the BDFIM is a brushless machine, which simplifies its maintenance; moreover, it can operate at lower speeds than the DFAM, which could benefit the design of the gear box [7].

As regards the physical configuration, the BDFIM has two isolated three-phase stator windings, the power winding and the control winding, which are supplied at different voltages and frequencies. Whereas the power winding has $p p$ pole pairs and is connected directly from the electrical network, the control winding has $p_{c}$ pole pairs and is excited from a variable voltagefrequency converter. The rotor has a specialized cage structure with a number of identical sections, or nests, $N_{r}$, which is equal to the sum of the pole pairs of the two stator windings. Each nest is composed of a set of concentric loops.

To introduce both stator windings in the same frame, it is necessary to use a slightly larger size in the BDFIM that in conventional induction machines. A comparison of $10 \mathrm{HP}$ machines is provided in [8].

Few references have been found on the evaluation of the magnetic flux density distribution (M.F.D.) in the BDFIM air gap. Perhaps, one of most rigorous mathematical models of the BDFIM was developed in [9], applying the complex conductor distribution for the rotor nests. This model, based on the generalized harmonic analysis, was developed for a specific configuration of the rotor nests (with isolated loops) through the calculation of equivalent impedances only useful for this configuration. The performance predictions made using this BDFIM model and the measurements made on a laboratory test machine were compared, resulting in very good correlation in key parameters such as torque, current in the power winding, and current in the control winding [10].

Although basic BDFIM theory exactly defines the number of nests in the cage structure (each nest can be constructed with different connections between bars), the bibliography lists some configurations with isolated nests, others with nests sharing bars, and even some with bars whose ends are connected by conducting rings [8], [9]. With these configurations, the calculation of 
the impedances involved in the model developed in [9] could be a complex process.

That is why the previous model might not be the most suitable tool for comparing the behavior of several BDFIMs with different rotor configurations when attempting to optimize their design. In this case, the study of the relationship between the rotor cage structure and the M.F.D. in the air gap could be very interesting to compare and to optimize the BDFIM design.

In this paper, we present an alternative formulation of the BDFIM operating principle based on the interaction of all magnetic fields created by the stator windings and the specialized rotor cage. For this purpose, the fundamental BDFIM equation is obtained using a simple formulation from idealized configurations of the stator windings and the rotor structure.

In addition, all the harmonic components of the M.F.D. in the air gap are perfectly defined in a BDFIM with idealized windings. By doing so, the paper provides a new test methodology and a standard that may be used to contrast the fields created by several real BDFIMs.

\section{Alternative Formulation}

The electromagnetic performance of the BDFIM was analyzed in [11] using simple equations. In that paper, the concept of "cross coupling" between both stator windings via the field created in the rotor nests was described. This "cross coupling" mechanism is essential for the suitable operation of the BDFIM in synchronous mode.

In this paper, all the magnetic field components created by the rotor nests are described using simple equations as well. It will be demonstrated that only two of these components cause the "cross coupling" mechanism, whereas the rest do not facilitate the operation of the BDFIM.

To simplify the analysis, the following assumptions are made: the magnetic circuit is linear, the supplies to both stator windings are three-phase balanced sinusoids, the air gap has a constant thickness, and finally, the value of the permeability of vacuum is negligible compared to the iron core permeability. Certain ideal conditions diverge from reality as the machine size increases. For example, in full-scale generators, the eccentricity of the shaft necessarily produces variable gaps, with effects on the M.F.D. in the air gap, which are not considered in this paper and that are left for future research. Nevertheless, the condition of linear magnetic circuit could be maintained in a full-scale generator if the design induction level is low.

To avoid the application of a generalized harmonic analysis, the specialized cage structure with $N_{r}$ nests is substituted by an ideal winding with $p_{r}$ pole pairs whose turns are arranged by the rotor surface, according to (1): ("N $N_{r}=p_{r}$ " will be demonstrated later)

$$
n_{r}=N \cos \left(p_{r} \alpha_{r}\right)
$$

where $N$ is the maximum number of conductors for the peak value of the ideal sinusoidal distribution, and $n_{r}$ is the number of turns located in angular position $\alpha_{r}$, which is expressed in a coordinate reference frame fixed to the rotor.
There exist certain analogies between this rotor concept and the rotor of the brushless doubly-fed reluctance machine [12], and these analogies still exist with the concept of mixed rotor of reluctances and nests, as was shown recently [13].

Given these initial considerations, in the next sections, we analyze the magnetic fields created by the stator windings, the "cross-coupling" mechanism and the "direct-coupling" mechanism.

\section{A. Magnetic Fields Created by the Stator Windings}

Two magnetic fields are generated in the BDFIM when the power and control windings are supplied with three-phase balanced voltages. The M.F.D. established in the air gap by both windings can be expressed as follows [9]:

$$
\begin{aligned}
& B_{p}\left(\alpha_{r}, t\right)=B_{p \mathrm{MAX}} \cos \left(\left(\omega_{p}-p_{p} \Omega_{r}\right) t-p_{p} \alpha_{r}\right) \\
& B_{c}\left(\alpha_{r}, t\right)=B_{c \mathrm{MAX}} \cos \left(\left(\omega_{c}-p_{c} \Omega_{r}\right) t-p_{c} \alpha_{r}\right) .
\end{aligned}
$$

In the previous equations, $\omega_{p}$ and $\omega_{c}$ are the supply angular frequencies of both the power and control stator windings, $\Omega_{r}$ is the rotor speed, and $\alpha_{r}$ the angle expressed in a coordinate reference frame fixed to the rotor.

The distribution $B_{p}\left(\alpha_{r}, t\right)$ induces an electromotive force (E.M.F.) in each rotor conductor that can be evaluated by applying Faraday's law

$$
\begin{aligned}
e_{r, p}\left(\alpha_{r}, t\right) & =-E_{r, p \mathrm{MAX}} \cos \left(\left(\omega_{p}-p_{p} \Omega_{r}\right) t-p_{p} \alpha_{r}\right) \\
E_{r, p \mathrm{MAX}} & =l\left(r\left(\omega_{p}-p_{p} \Omega_{r}\right)\right) B_{p \mathrm{MAX}}
\end{aligned}
$$

where $l$ is the conductor length and $r$ the rotor radius. The suffixes $r, p$ are employed to designate the rotor magnitudes that are generated by the field created when the power winding is excited.

The induced E.M.F. generates a current in the conductor with the same angular frequency and a phase angle that is dependent on the impedance angle of the conductor. However, in order to determine the pole pair number of the magnetic field components and their speeds, it is not necessary to deal with the phase angle

$$
i_{r, p}\left(\alpha_{r}, t\right)=I_{r, p \mathrm{MAX}} \cos \left(\left(\omega_{p}-p_{p} \Omega_{r}\right) t-p_{p} \alpha_{r}\right) .
$$

This current produces a magnetomotive force (M.M.F.) whose expression is

$$
\begin{aligned}
& \operatorname{M.M.F}_{r, p}\left(\alpha_{r}, t\right)=n_{r}\left(\alpha_{r}\right) I_{r, p}\left(\alpha_{r}, t\right) \\
& =N \cos \left(p_{r} \alpha_{r}\right) I_{r, p \mathrm{MAX}} \cos \left(\left(\omega_{p}-p_{p} \Omega_{r}\right) t-p_{p} \alpha_{r}\right)
\end{aligned}
$$

Applying Ampere's law, the M.F.D. established by the rotor currents is determined by the M.M.F.

$$
\begin{aligned}
& B_{r, p}\left(\alpha_{r}, t\right) \\
& =\frac{\mu_{0}}{\delta} N I_{r, p \mathrm{MAX}} \cos \left(p_{r} \alpha_{r}\right) \cos \left(\left(\omega_{p}-p_{p} \Omega_{r}\right) t-p_{p} \alpha_{r}\right)
\end{aligned}
$$

where $\mu_{0}$ is the permeability of vacuum and $\delta$ is the air gap length. Substituting in (8) yields

$$
B_{r, p}\left(\alpha_{r}, t\right)=B_{r, p 1}\left(\alpha_{r}, t\right)+B_{r, p 2}\left(\alpha_{r}, t\right)
$$


with

$B_{r, p l}\left(\alpha_{r}, t\right)=\frac{1}{2} B_{r, p \mathrm{MAX}} \cos \left(\left(\omega_{p}-p_{p} \Omega_{r}\right) t-\left(p_{p}+p_{r}\right) \alpha_{r}\right)$

$B_{r, p 2}\left(\alpha_{r}, t\right)=\frac{1}{2} B_{r, p \mathrm{MAX}} \cos \left(\left(\omega_{p}-p_{p} \Omega_{r}\right) t-\left(p_{p}-p_{r}\right) \alpha_{r}\right)$

Using a similar procedure, starting from $B_{c}\left(n_{r}, t\right)$, the M.F.D. established by the rotor currents is determined as

$$
B_{r, c}\left(\alpha_{r}, t\right)=B_{r, c 1}\left(\alpha_{r}, t\right)+B_{r, c 2}\left(\alpha_{r}, t\right)
$$

with

$B_{r, c l}\left(\alpha_{r}, t\right)=\frac{1}{2} B_{r, c \mathrm{MAX}} \cos \left(\left(\omega_{c}-p_{c} \Omega_{r}\right) t-\left(p_{c}+p_{r}\right) \alpha_{r}\right)$

$B_{r, c 2}\left(\alpha_{r}, t\right)=\frac{1}{2} B_{r, c \mathrm{MAX}} \cos \left(\left(\omega_{c}-p_{c} \Omega_{r}\right) t-\left(p_{c}-p_{r}\right) \alpha_{r}\right)$.

The suffixes $r, c$ are used to designate the rotor magnitudes that are generated by the field created when the control winding is excited.

\section{B. Analysis of the "Cross Coupling"}

The operation of the BDFIM in synchronous mode is due to the "cross-coupling" mechanism that appears between both stator windings [11]. The "cross-coupling" mechanism occurs when the following conditions are observed.

1) "Cross-Coupling" Mechanism From the Power Winding to the Control Winding: One of the M.F.D.s $B_{r, p 1}$ or $B_{r, p 2}$ should have the same number of poles as the M.F.D. $B_{c}$ and it should rotate at the same speed. In low-speed drives like wind turbines, a $p_{p}$ larger than $p_{c}$ is chosen. In this case, the stator and rotor coupling takes place by means of the M.F.D. $B_{r, p 2}$ [14]

$$
\begin{aligned}
& \cos \left(\left(\omega_{c}-p_{c} \Omega_{r}\right) t-p_{c} \alpha_{r}\right) \\
& \quad=\cos \left(\left(\omega_{p}-p_{p} \Omega_{r}\right) t-\left(p_{p}-p_{r}\right) \alpha_{r}\right) .
\end{aligned}
$$

Since $\cos (\theta)=\cos (-\theta)$, it follows that

$$
\begin{gathered}
\omega_{c}-p_{c} \Omega_{r}=-\left(\omega_{p}-p_{p} \Omega_{r}\right), \quad p_{c}=-\left(p_{p}-p_{r}\right) \\
\Omega_{r}=\frac{\omega_{p}+\omega_{c}}{p_{p}+p_{c}}, \quad p_{p}+p_{c}=p_{r}
\end{gathered}
$$

2) "Cross-Coupling" Mechanism From the Control Winding to the Power Winding: One of the M.F.D.s $B_{r, c 1}$ or $B_{r, c 2}$ should have the same number of poles as the M.F.D. $B_{p}$ and it should rotate at the same speed. In this case, the coupling takes place through the M.F.D. $B_{r, c 2}[14]$

$$
\begin{aligned}
& \cos \left(\left(\omega_{p}-p_{p} \Omega_{r}\right) t-p_{p} \alpha_{r}\right) \\
& \quad=\cos \left(\left(\omega_{c}-p_{c} \Omega_{r}\right) t-\left(p_{c}-p_{r}\right) \alpha_{r}\right) .
\end{aligned}
$$

Since $\cos (\theta)=\cos (-\theta)$, we obtain

$$
\begin{gathered}
\omega_{p}-p_{p} \Omega_{r}=-\left(\omega_{c}-p_{c} \Omega_{r}\right), \quad p_{p}=-\left(p_{c}-p_{r}\right) \\
\Omega_{r}=\frac{\omega_{p}+\omega_{c}}{p_{p}+p_{c}}, \quad p_{p}+p_{c}=p_{r} .
\end{gathered}
$$

Therefore, the "cross-coupling" mechanism only takes place under the operating condition indicated in (16) and (18). This condition is the same as the one presented in [9] and [11], but it has been obtained in a different way, and it is the basic equation of the operation of the BDFIM in synchronous mode. This operating mode is characterized by having a speed that does not depend on the torque, and is only dependent on the frequency of the control winding

$$
\Omega_{r}=\frac{\omega_{p} \pm \omega_{c}}{p_{p}+p_{c}}=2 \pi \frac{f_{p} \pm f_{c}}{p_{p}+p_{c}} .
$$

In the previous equation, the (-) sign indicates that the sequence of the three-phase supply voltage for the control winding is different from the power winding sequence. The speed obtained when the control winding is excited with direct current $\left(f_{c}=0\right)$ is called "synchronism natural speed" or "natural speed $\left(\Omega_{N}\right)$.

The M.F.D.s $B_{r, p 1}$ with $\left(p_{p}+p_{r}\right)$ pole pairs and $B_{r, c 1}$ with $\left(p_{c}+p_{r}\right)$ pole pairs constitute part of the leakage flux of the BDFIM, and they rotate in the machine in the same direction as $B_{p}$ and $B_{c}$, respectively (with respect to a coordinate reference frame fixed to the rotor).

\section{Analysis of the "Direct Coupling"}

In the operation of the BDFIM in synchronous mode, a "direct coupling" mechanism also appears, as in the conventional induction machine. According to this mechanism, the rotor winding must generate a magnetic field with the same pole pair number as the stator field and same rotational speed. However, the M.F.D.s $B_{r, p \perp}$ and $B_{r, c 1}$ have a pole pair number different from those of the "direct coupling" field $\left(p_{p}\right.$ and $\left.p_{c}\right)$.

To justify the "direct coupling" mechanism with this alternative formulation, it is necessary to provide or conduct a more detailed analysis of all the magnetic fields. Starting from the M.F.D.s $B_{r, p 1}$ and $B_{r, p 2}$, generated by $B_{p}$, and following the mechanism of appearance of the rotor fields that has been described, each M.F.D. generates other M.F.D.s

1) $M . F, D, B_{r, p 1}\left(\alpha_{r}, t\right)$ : It generates two other M.F.D.s $B_{\alpha, p 11}\left(\alpha_{r}, t\right)$ and $B_{r, p 12}\left(\alpha_{r}, t\right)$, due to its interaction with the rotor winding

$$
\begin{aligned}
& B_{r p, 11}\left(\alpha_{r}, t\right)=B_{r p, 11 \mathrm{MAX}} \cos \left(\left(\omega_{p}-p_{p} \Omega_{r}\right) t\right. \\
& \left.-\left(\left(p_{p}+p_{r}\right)+p_{r}\right) \alpha_{r}\right) \\
& B_{r p, 1 \perp}\left(\alpha_{r}, t\right)=B_{r p, 11 \mathrm{MAX}} \cos \left(\left(\omega_{p}-p_{p} \Omega_{r}\right) t\right. \\
& -\left(\left(p_{p}+2 p_{r}\right) \alpha_{r}\right) \\
& B_{r p, 12}\left(\alpha_{r}, t\right)=B_{r p, 12 \mathrm{MAX}} \cos \left(\left(\omega_{p}-p_{p} \Omega_{r}\right) t\right. \\
& \left.-\left(\left(p_{p}+p_{r}\right)-p_{r}\right) \alpha_{r}\right) \\
& B_{r p, 12}\left(\alpha_{r}, t\right)=B_{r p, 12 \mathrm{MAX}} \cos \left(\left(\omega_{p}-p_{p} \Omega_{r}\right) t-p_{p} \alpha_{r}\right)
\end{aligned}
$$


2) M.F.D. $B_{r, p 2}\left(\alpha_{r}, t\right)$ : It generates two other M.F.D.s $B_{r, p 21}\left(\alpha_{r}, t\right)$ and $B_{r, p 22}\left(\alpha_{r}, t\right)$, due to its interaction with the rotor winding

$$
\begin{aligned}
B_{r p, 21}\left(\alpha_{r}, t\right)= & B_{r p, 21 \mathrm{MAX}} \cos \left(\left(\omega_{p}-p_{p} \Omega_{r}\right) t\right. \\
& \left.-\left(\left(p_{p}-p_{r}\right)+p_{r}\right) \alpha_{r}\right) \\
B_{r p, 21}\left(\alpha_{r}, t\right)= & B_{r p, 21 \mathrm{MAX}} \cos \left(\left(\omega_{p}-p_{p} \Omega_{r}\right) t-p_{p} \alpha_{r}\right) \\
B_{r p, 22}\left(\alpha_{r}, t\right)= & B_{r p, 22 \mathrm{MAX}} \cos \left(\left(\omega_{p}-p_{p} \Omega_{r}\right) t\right. \\
& \left.-\left(\left(p_{p}-p_{r}\right)-p_{r}\right) \alpha_{r}\right)
\end{aligned}
$$

According to (19)

$$
\begin{aligned}
B_{r p, 22}\left(\alpha_{r}, t\right)= & B_{r p, 22 \mathrm{MAX}} \cos \left(-\left(\omega_{c}-p_{c} \Omega_{r}\right) t\right. \\
& \left.-\left(-\left(p_{c}+p_{r}\right)\right) \alpha_{r}\right) .
\end{aligned}
$$

The M.F.D.s $B_{r, p 12}$ and $B_{r, p 21}$ have the same number of pole pairs $\left(p_{p}\right)$ as the M.F.D. $B_{p}$, and they rotate at the same speed, and therefore, the "direct coupling" mechanism occurs.

The M.F.D.s $B_{r, p 11}$ with $\left(p_{p}+2 p_{r}\right)$ pole pairs and $B_{r, c 22}$ with $\left(p_{c}+p_{r}\right)$ pole pairs constitute part of the leakage flux of the BDFIM. These M.F.D.s rotate around the air gap in the same direction of rotation as $B_{p}$ and $B_{c}$, respectively (with respect to a coordinate reference frame fixed to the rotor).

According to this mechanism, other M.F.D.s are recurrently generated by the rotor M.F.D.s. These new M.F.D.s have smaller amplitudes, they constitute part of the leakage flux of the BDFIM, and can be separated into two families.

1) M.F.D.s with $p_{p}+n p_{r}$ pole pairs $(n=1,2,3, \ldots)$ and the same direction of rotation as the M.F.D. $B_{p}$.

2) M.F.D.s with $p_{c}+n p_{r}$ pole pairs $(n=1,2,3, \ldots)$ and the same direction of rotation as the M.F.D. $B_{c}$.

With a similar reasoning and starting from the M.F.D.s $B_{r, c 1}$ and $B_{r, c 2}$ that are generated by rotor currents induced by $B_{c}$, we obtain the following.

1) M.F.D.s with $p_{p}$ pole pairs and the same rotational speed as the M.F.D. $B_{p}$ that establishes the "cross-coupling" mechanism.

2) M.F.D.s with $p_{c}$ pole pairs and the same rotational speed as the M.F.D. $B_{c}$ that establishes the "direct coupling" mechanism.

3) M.F.D.s with $p_{c}+n p_{r}$ pole pairs $(n=1,2,3, \ldots)$ and the same direction of rotation as the M.F.D. $B_{c}$ that are part of the leakage flux of the BDFIM.

4) M.F.D.s with $p_{p}+n p_{r}$ pole pair $(n=1,2,3, \ldots)$ and the same direction of rotation as the M.F.D. $B_{p}$ that are part of the leakage flux of the BDFIM.

Thus, according to (10), (11), (16), and (20)-(23), a set of M.F.D. components with different pole pair numbers is generated starting from the M.F.D. of the power winding $B_{p}$, which is coupled with the power winding (direct coupling) and with the control winding (cross coupling). Fig. 1 shows these M.F.D. components with their pole pair numbers in brackets.

For the M.F.D.s generated by $B_{c}$, it might obtain a similar figure by changing the suffixes " $p$ " and " $c$."

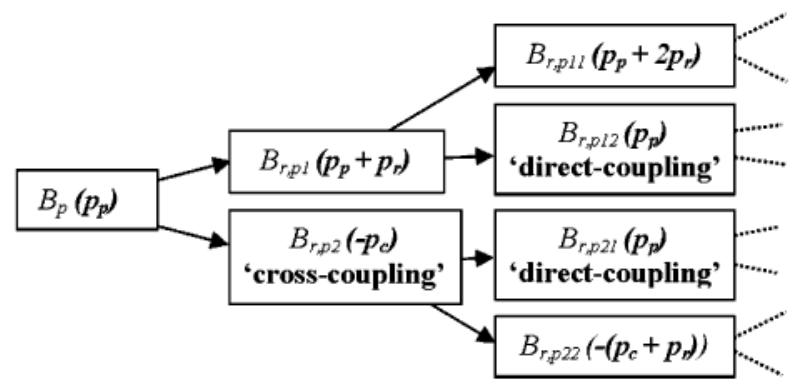

Fig. 1. M.F.D.s generated by $B_{p}$.
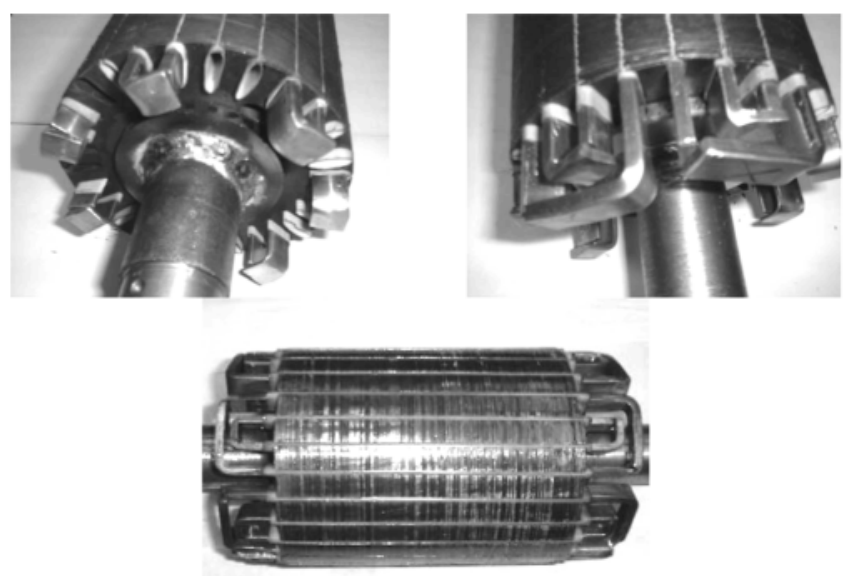

Fig. 2. Rotor of the experimental BDFIM. It has seven nests with two loops per nest.

\section{EXPERIMENTAL RESULTS}

\section{A. Experimental Machine}

The power winding ( $p_{p}=5$ ) and the control winding $\left(p_{c}=2\right)$ have been wound in the iron stator core from a conventional induction machine (length $190 \mathrm{~mm}$; inner diameter $140 \mathrm{~mm} ; 36$ trapezoidal slots). Both stator windings are double-layer located in all the stator slots. The choice of $p_{p}$ and $p_{c}$ numbers is the result of the theoretical study presented in [15].

The 28-slot rotor core comes from the same conventional induction machine (length $190 \mathrm{~mm}$; diameter $139.4 \mathrm{~mm}$ ). It has been furnished with $7(5+2)$ nests, each consisting of two loops that were fabricated by placing several straight copper bars in the slots. These rotor bars are insulated from the rotor core to avoid the interbar currents that degrade the performance of the BDFIM [16]. The rotor of the resulting prototype is shown in Fig. 2 in different stages of its manufacturing process.

The power winding and the control winding must have different pole pair numbers in order to avoid a direct magnetic coupling. In this paper, we have chosen two prime numbers (5 and 2) for the pole pair so as to avoid the possible direct magnetic coupling of the spatial harmonics of the power and the control windings as well.

The main design details of the resulting machine windings are shown in Table I. 
TABLE I

DESIGN DETAILS OF THE B.D.F.I.M. PROTOTYPE

\begin{tabular}{|c|c|c|c|c|c|}
\hline \multicolumn{2}{|c|}{$\begin{array}{c}\text { Winding } \\
\text { Characteristics }\end{array}$} & Conductor & $\begin{array}{l}\text { Rated } \\
\text { Volt. } \\
\text { [V] }\end{array}$ & $\begin{array}{l}\text { Rated } \\
\text { Freq. } \\
{[\mathrm{Hz}]}\end{array}$ & $\begin{array}{c}\text { Rated Stator Flux } \\
\text { Density [T] } \\
\text { Yoke / Tooth }\end{array}$ \\
\hline $\begin{array}{l}\text { Power } \\
\text { winding } \\
\left(\mathrm{p}_{\mathrm{p}}=5\right)\end{array}$ & $\begin{array}{c}\text { Double-layer } \\
43 \text { turns/coil }\end{array}$ & $\begin{array}{c}2 \times \text { AWG } 23 \\
\text { Fill factor } \\
0.45\end{array}$ & 230 & 50 & $0.4 / 1.1$ \\
\hline $\begin{array}{l}\text { Control } \\
\text { winding } \\
\left(\mathrm{p}_{\mathrm{c}}=2\right)\end{array}$ & $\begin{array}{c}\text { Double-layer } \\
35 \text { turns/coil }\end{array}$ & $\begin{array}{c}1 \times \text { AWG } 24 \\
\text { Fill factor } \\
0.44\end{array}$ & 230 & 50 & $0.5 / 0.5$ \\
\hline $\begin{array}{c}\text { Rotor } \\
\text { 'cage' } \\
\left(\mathrm{N}_{\mathrm{r}}=7\right)\end{array}$ & $\begin{array}{c}\text { Single-layer } \\
2 \text { loops/nest } \\
1 \text { turn/loop }\end{array}$ & $\begin{array}{c}\text { Shaped } \\
\text { Copper bars } \\
\text { (Fig. 1) }\end{array}$ & - & - & - \\
\hline
\end{tabular}

The experimental BDFIM is mechanically coupled to a dc machine. The power winding is supplied from a $50 \mathrm{~Hz}$ electrical network via an autotransformer and its control winding is supplied from a variable-frequency variable voltage generator set. This generator set comprises a high-inertia synchronous generator coupled to a regulated dc motor. The synchronous generator is used in preference to an electronic converter to avoid harmonics in the supply.

\section{B. Tests Description}

The main objective of the tests is to demonstrate the existence of the M.F.D.s that were predicted by the proposed new formulation. To achieve this objective, it is necessary to analyze separately the influence of each stator winding on the magnetic field created by the rotor nests.

The tests were carried out with the experimental machine in the following conditions.

1) One stator winding is excited while the other one is in an open-circuit condition.

2) Its speed is fixed by the coupled dc machine.

3) The E.M.F. induced in a search coil placed on the stator is recorded by means of an oscilloscope with 25 MSPS acquisition rate and $60 \mathrm{MHz}$ bandwidth. This search coil is placed on the inner diameter surface of the stator, near the slot opening, close to the air gap whose M.F.D. is to be verified.

The experimental results will be presented for low excitation voltages in order to avoid the effects of magnetic saturation in the M.F.D. Moreover, the experimental machine is designed in conditions of simultaneous excitation of both stator windings, whereas in these tests, only one of them is supplied.

For determining the M.F.D. components in the experimental machine, a frequency analysis of the E.M.F. induced in the search coil is performed. To verify the pole pair number of M.F.D. components, the tests are carried out at several speeds of the rotor.

In the next section, several test results are presented exciting the power winding or the control winding.

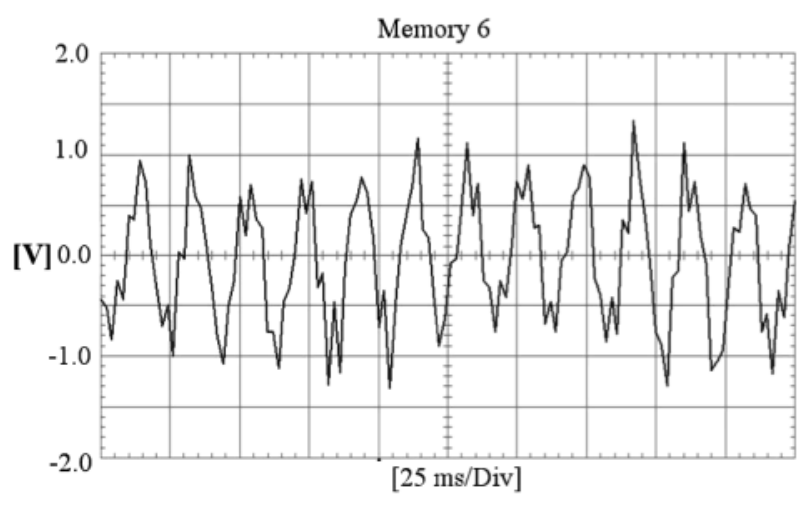

Fig. 3. Measured E.M.F. in the search coil with $n_{r}=478.15 \mathrm{r} / \mathrm{min}$

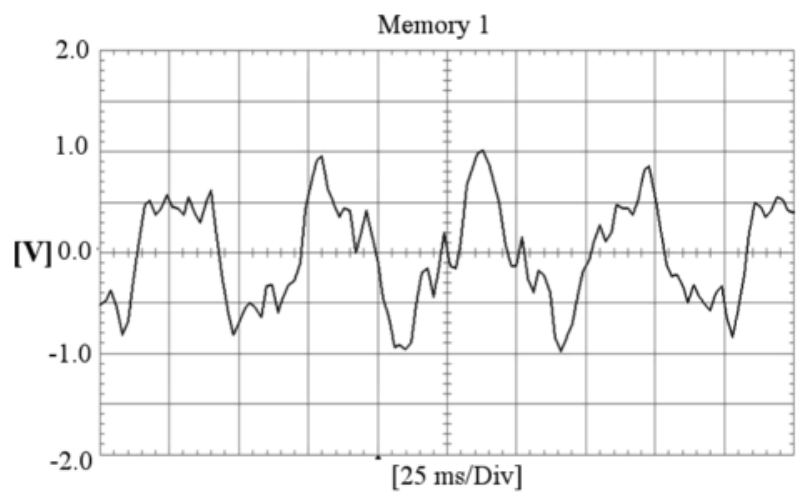

Fig. 4. Measured E.M.F. in the search coil for $n_{r}=274.5 \mathrm{r} / \mathrm{min}$.

\section{Test Results}

1) Exciting the Power Winding: The tests were carried out at a constant power winding voltage, $170 \mathrm{~V}$, and a power winding frequency of $50 \mathrm{~Hz}$, with the control winding in an open circuit. For these tests, a search coil with four turns and the same pitch as the control winding (eight teeth) was used.

According to the proposed formulation, the M.F.D. in the air gap of the BDFIM should have the following components.

1) A 5-pole-pair component $\left(p_{p}\right)$ that couples with the power winding ("direct-coupling"), thereby inducing an E.M.F. component of $50 \mathrm{~Hz}$ in the search coil.

2) A 2-pole-pair component $\left(p_{c}\right)$ that couples with the control winding ("cross-coupling"), thereby inducing an E.M.F. component in the search coil with the frequency of the control winding excitation (in synchronous mode operation)

$$
\begin{aligned}
\Omega_{r}=2 \pi \frac{f_{p} \pm f_{c}}{p_{p}+p_{c}} & \rightarrow \pm f_{c}=\frac{\Omega_{r}}{2 \pi}\left(p_{p}+p_{c}\right)-f_{p} \\
& \rightarrow \pm f_{c}=\frac{n_{r}}{60}\left(p_{p}+p_{c}\right)-f_{p}
\end{aligned}
$$

In the previous equation, $n_{r}$ is the rotor speed (in $\mathrm{r} / \mathrm{min}$ ) and the $(+)$ sign is valid when $n_{r}>n_{N}$ whereas the $(-)$ sign is used if $n_{r}<n_{N}$. 


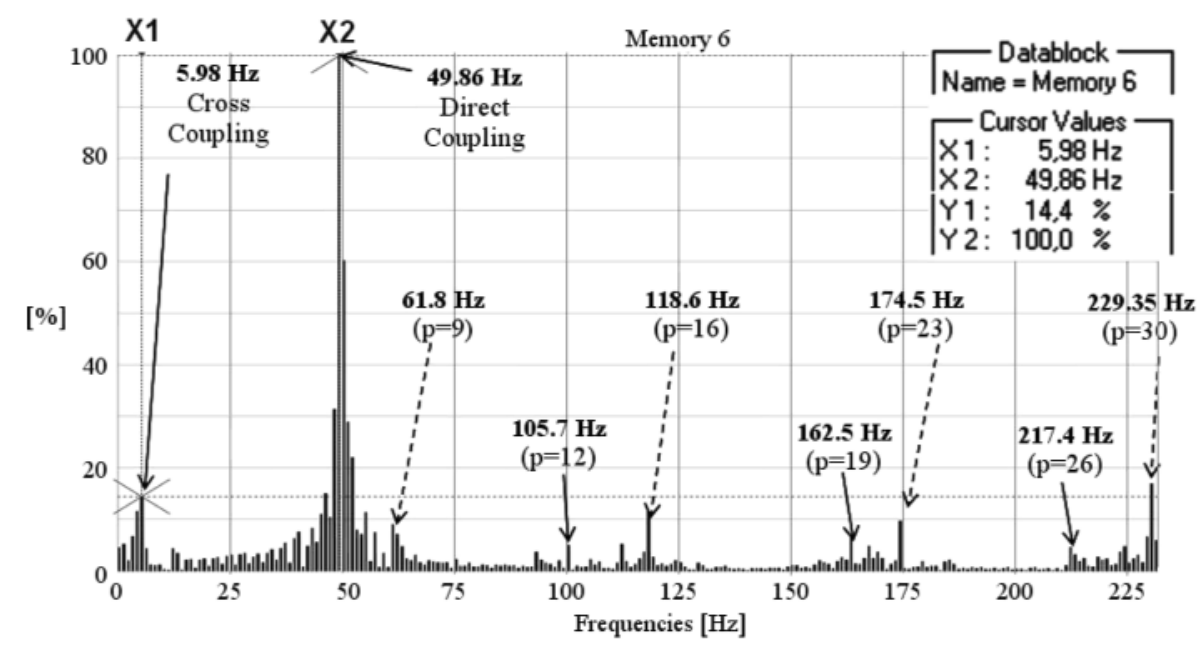

Fig. 5. Harmonic decomposition of the measured E.M.F. with $n_{r}=478.15 \mathrm{r} / \mathrm{min}$.

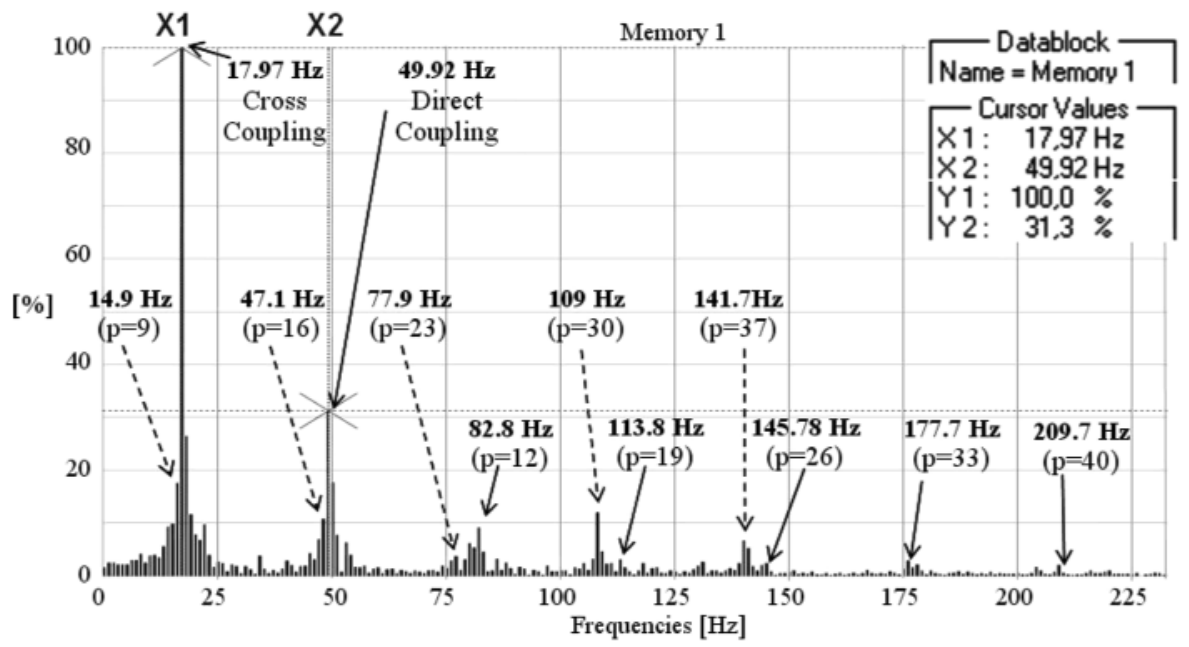

Fig. 6. Harmonic decomposition of the measured E.M.F. with $n_{r}=274.5 \mathrm{r} / \mathrm{min}$.

TABLE II

Calculated Frequencies (in HertZ) and Measured Frequencies of the COMPONENTS OF THE INDUCED E.M.F. TEST WITH SPEED $478.15 \mathrm{r} / \mathrm{min}$

\begin{tabular}{|c|c|c|c|c|c|c|c|c|c|c|}
\hline \multirow{3}{*}{$\begin{array}{l}\text { Rotor } \\
\text { speed } \\
\mathbf{4 7 8 . 1 5} \\
\text { [r.p.m] }\end{array}$} & \multicolumn{5}{|c|}{$p_{p}+n \cdot p_{r} \quad$ component of M.F.D } & \multicolumn{5}{|c|}{$p_{c}+n \cdot p_{r} \quad$ component of M.F.D } \\
\hline & 12 & 19 & 26 & 33 & 40 & 9 & 16 & 23 & 30 & 37 \\
\hline & \multicolumn{10}{|c|}{ Frequency $f_{e}[\mathrm{~Hz}]$ of the E.M.F in the search coil } \\
\hline $\begin{array}{l}\text { Calculated } \\
\text { eq. (25) }\end{array}$ & 105.8 & 161.6 & 217.4 & 273.1 & 328.9 & 61.6 & 117.4 & 173.1 & 228.9 & 290.2 \\
\hline $\begin{array}{l}\text { Measured } \\
\text { Fig. } 5\end{array}$ & 105.7 & 162.5 & 217.4 & - & - & 61.8 & 118.6 & 174.4 & 229.35 & - \\
\hline $\begin{array}{l}\text { Relative } \\
\text { error [\%] }\end{array}$ & 0.1 & -0.6 & 0.0 & - & - & -0.3 & -1.0 & -0.8 & -0.2 & - \\
\hline
\end{tabular}

3) Components of $12,19,26,33,40, \ldots, p_{p}+n p_{r}$ pole pairs with the same direction of rotation as the M.F.D. $B_{p}$, and components of $9,16,23,30,37, \ldots, p_{c}+n p_{r}$ pole pairs with the same direction of rotation as the M.F.D. $B_{c}$. A generic M.F.D. with $p_{i}$ pole pairs, which has been generated by the rotor current, induces an E.M.F. in the search
TABLE III

Calculated Frequencies (in HertZ) and Measured Frequencies OF THE COMPONENTS OF THE INDUCED E.M.F. TEST WITH SPEED $274.5 \mathrm{r} / \mathrm{min}$

\begin{tabular}{|c|c|c|c|c|c|c|c|c|c|c|}
\hline \multirow{3}{*}{$\begin{array}{c}\text { Rotor } \\
\text { speed } \\
\mathbf{2 7 4 . 5} \\
\text { [r.p.m] }\end{array}$} & \multicolumn{5}{|c|}{$p_{p}+n \cdot p_{r} \quad$ component of M.F.D } & \multicolumn{5}{|c|}{$p_{c}+n p_{r} \quad$ component of M.F.D } \\
\hline & 12 & 19 & 26 & 33 & 40 & 9 & 16 & 23 & 30 & 37 \\
\hline & \multicolumn{10}{|c|}{ Frequency $f_{e}[\mathrm{~Hz}]$ of the E.M.F in the search coil } \\
\hline $\begin{array}{l}\text { Calculated } \\
\text { eq. (25) }\end{array}$ & 82.0 & 114.1 & 146.1 & 178.1 & 210.1 & 14.0 & 46.1 & 78.1 & 110.1 & 142.1 \\
\hline $\begin{array}{l}\text { Measured } \\
\text { Fig. } 6\end{array}$ & 82.8 & 113.8 & 145.78 & 177.7 & 209.7 & 14.9 & 47.1 & 77.9 & 109 & 141.7 \\
\hline $\begin{array}{l}\text { Relative } \\
\text { error [\%] }\end{array}$ & -1.0 & 0.3 & 0.2 & 0.2 & 0.2 & -6.4 & -2.2 & 0.3 & 1.0 & 0.3 \\
\hline
\end{tabular}

coil whose frequency $f_{e}$ is equal to

$$
\begin{aligned}
f_{e}=\frac{p_{i}}{60} n_{e} & \rightarrow f_{e}=\frac{p_{i}}{60}\left[n_{r} \pm 60 \frac{s_{p} f_{p}}{p_{i}}\right] \\
\rightarrow f_{e} & =\frac{p_{i}}{60} n_{r} \pm s_{p} f_{p} .
\end{aligned}
$$


In the previous equation, $s_{p}$ is the slip with respect to the M.F.D. $B_{p}$. If the generic M.F.D. rotates in the same direction as $B_{p}$, then the $(+)$ sign is valid, else the (-) sign may be used.

Several tests at different speed values, over and under the natural speed $\Omega_{N}\left(n_{N}\right)$, were conducted

$$
\Omega_{N}=2 \pi \frac{50}{5+2}=44.88 \mathrm{~s}^{-1}\left(n_{N}=428.57 \mathrm{r} / \mathrm{min}\right) .
$$

As an example, the test results with 478.15 and $274.5 \mathrm{r} / \mathrm{min}$ are presented. For each test, the E.M.F. induced in the search coil was recorded (Figs. 3 and 4). Their harmonic decompositions are presented in Figs. 5 and 6, respectively. In these figures, the harmonic components predicted by the alternative formulation are marked.

Applying (24) to the $478.15 \mathrm{r} / \mathrm{min}$ speed yields a frequency of $5.8 \mathrm{~Hz}$ for the cross-coupling component of the M.F.D. The remaining components induce frequencies according to (25). In Table II, these calculated frequencies are shown close to the frequencies that were measured in the test (Fig. 5).

Likewise, a speed of $274.5 \mathrm{r} / \mathrm{min}$ yields a frequency of $18 \mathrm{~Hz}$ for the cross-coupling component. Table III shows the calculated (25) and the measured frequencies (Fig. 6) that were induced by the remaining M.F.D. components.

In Figs. 5 and 6, we can see two components of $5.98 \mathrm{~Hz}$ and $17.97 \mathrm{~Hz}$, respectively. Note the good agreement between these components and the calculated frequencies of the cross-coupling components $(5.8 \mathrm{~Hz}$ and $18 \mathrm{~Hz})$.

There is also good agreement in the remaining components between the calculated frequencies predicted by the new formulation and the frequencies measured in the tests (Tables II and III).

2) Exciting the Control Winding: After validating the proposed formulation regarding the field created by the power winding, in this section, it is confirmed regarding the field created by the control winding. According to the proposed formulation, the M.F.D. in the air gap of the BDFIM should have the following components: one 2-pole-pair component $\left(p_{c}\right)$ ("directcoupling"), one 5-pole-pair component ( $\left.p_{p}\right)$ ("cross-coupling"), components of $9,16,23,30,37, \ldots, p_{c}+n p_{r}$ pole pair, and components of $12,19,26,33,40, \ldots, p_{p}+n p_{r}$ pole pair.

In this case, a generic M.F.D. with $p_{i}$ pole pair induces in the search coil an E.M.F. whose frequency $f_{e}$ is equal to

$$
f_{e}=\frac{p_{i}}{60} n_{r} \pm s_{c} f_{c} .
$$

As an example, the test results with $478.15 \mathrm{r} / \mathrm{min}$ are presented. In this test, the control winding was excited to $37 \mathrm{~V}$ and $6 \mathrm{~Hz}$ and a search coil with four turns and the same pitch as the power winding (three teeth) was utilized. The E.M.F. induced in the search coil was recorded (Fig. 7) and its harmonic decomposition is presented in Fig. 8.

Applying (24) to the $478.15 \mathrm{r} / \mathrm{min}$ speed and $f_{c}=6 \mathrm{~Hz}$ yields a frequency of $49.78 \mathrm{~Hz}$ for the cross-coupling component of the M.F.D. The remaining components induce frequencies according to (26). In Table IV, these calculated frequencies are shown close to the frequencies that were measured in the test (Fig. 8).

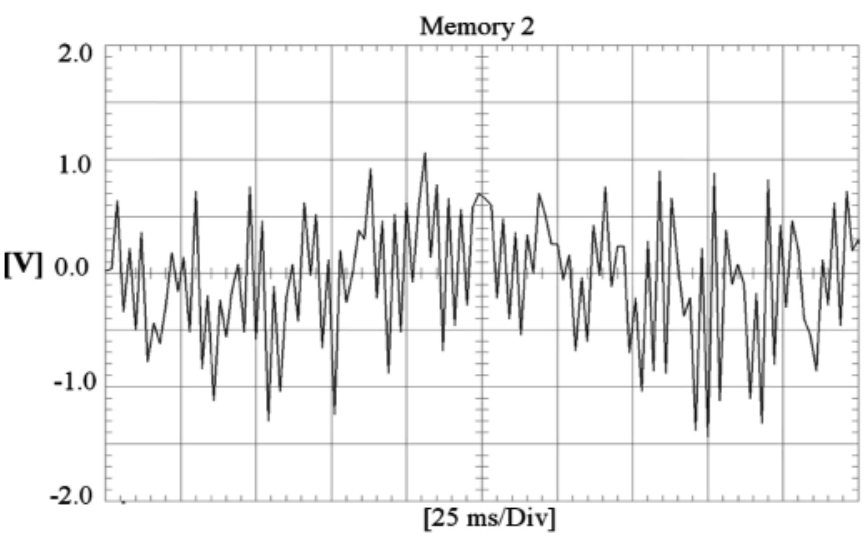

Fig. 7. Measured E.M.F. in the search coil with $n_{r}=478.15 \mathrm{r} / \mathrm{min}$, when the control winding is excited.

TABLE IV

Calculated Frequencies (IN HERTZ) AND MEASUREd FREQuENCIES OF THE COMPONENTS OF THE INDUCED E.M.F. TEST WITH SPEED $478.15 \mathrm{r} / \mathrm{min}$, When

\begin{tabular}{|c|c|c|c|c|c|c|c|c|c|c|}
\hline \multirow{3}{*}{$\begin{array}{l}\text { Rotor } \\
\text { speed } \\
\mathbf{4 7 8 . 1 5} \\
\text { [r.p.m] }\end{array}$} & \multicolumn{5}{|c|}{$p_{p}+n \cdot p_{r}$ component of M.F.D } & \multicolumn{5}{|c|}{$p_{c}+n \cdot p_{r} \quad$ component of M.F.D } \\
\hline & 12 & 19 & 26 & 33 & 40 & 9 & 16 & 23 & 30 & 37 \\
\hline & \multicolumn{10}{|c|}{ Frequency $f_{e}[\mathrm{~Hz}]$ of the E.M.F in the search coil } \\
\hline $\begin{array}{l}\text { Calculated } \\
\text { eq. (26) }\end{array}$ & 105.6 & 161.3 & 217.1 & 272.9 & 328.7 & 61.8 & 117.6 & 173.3 & 229.1 & 290.2 \\
\hline $\begin{array}{c}\text { Measured } \\
\text { Fig. } 8\end{array}$ & 105.1 & 160.6 & 218.1 & - & - & 61.5 & 118 & 171.5 & 227.0 & - \\
\hline $\begin{array}{c}\text { Relative } \\
\text { error [\%] }\end{array}$ & -0.5 & -0.4 & 0.5 & - & - & -0.5 & 0.3 & 1.0 & -0.9 & - \\
\hline
\end{tabular}
the Control Winding Is Excited

In Fig. 8, a component of $49.56 \mathrm{~Hz}$ can be observed. Note the good agreement between this component and the calculated frequency of the cross-coupling component $(49.78 \mathrm{~Hz})$.

There is also good agreement in the remaining components between the calculated frequencies predicted by the new formulation and the frequencies measured in the test (Table IV).

Therefore, the new formulation proposed in this paper is validated. These frequencies establish the standard that characterizes the magnetic field component generated with the combination of $p_{p}=5$ and $p_{c}=2$ in the BDFIM.

The new formulation is valid for any BDFIM configuration, regardless of its size, rating, pole pair number, type of magnetic circuit, etc., because only the condition of sinusoidal distributed windings was imposed in developing it.

Nevertheless, the test results show additional frequencies not predicted by the proposed formulation. These frequencies are due to the harmonic fields that appear because the rotor cage and the stator windings are not ideal windings (i.e., they are not sinusoidally distributed.

If the rotor configuration differs from that of the nested rotor that has been utilized in this paper, other additional frequencies could appear, in addition to those predicted by the proposed theory. 


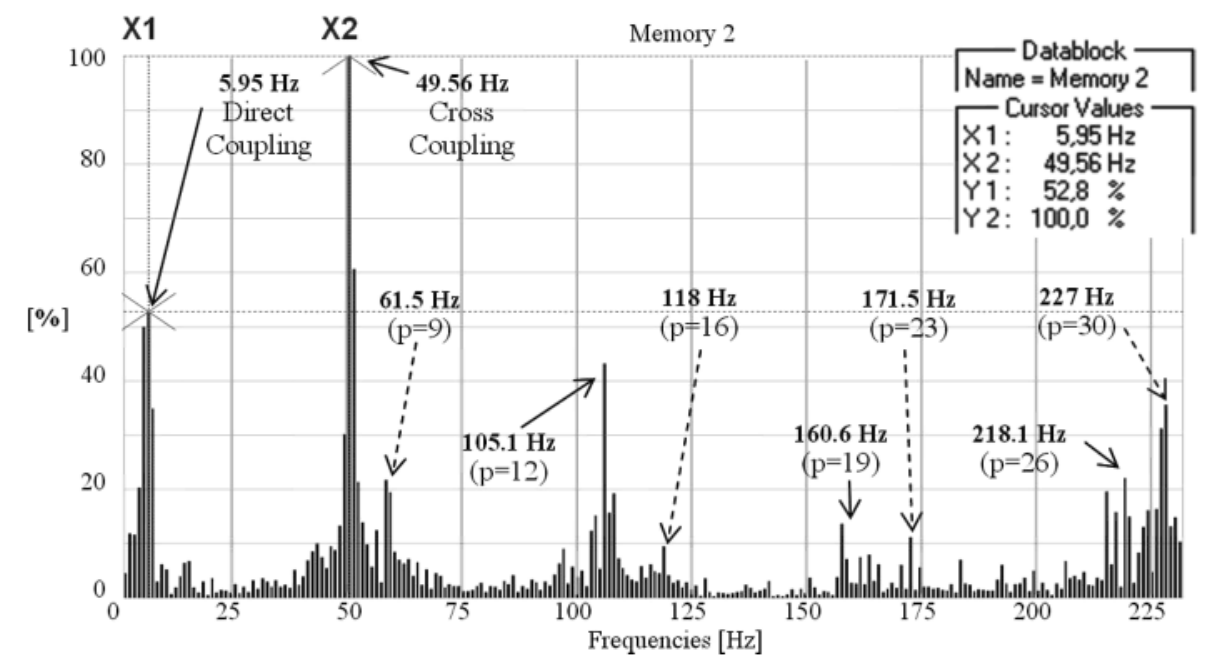

Fig. 8. Harmonic decomposition of the measured E.M.F. with $n_{r}=478.15 \mathrm{r} / \mathrm{min}$, when the control winding is excited.

\section{CONCLUSION}

At the present time, the development of wind power generation in the world could be an important incentive for the application of BDFIM. It could be an alternative to the DFIM in variable-speed wind generation systems. Thus, research on improving this machine could have important implications for wind power generation.

In this paper, we presented an alternative formulation of the operating principle of BDFIM in synchronous mode. This new formulation was used to deduce not only the well-known conditions for operation in synchronous mode, but also to evaluate the M.F.D. in the BDFIM air gap. The harmonic components of the M.F.D. were characterized according to their pole pair numbers and rotational speeds. Finally, the proposed formulation was validated in a prototype test machine.

A way to improve the performance of the BDFIM could be through the optimization of the rotor configuration. To this end, the M.F.D. characterization obtained in this paper could be considered a pattern, which could be used in comparing the various magnetic fields created by different rotor configurations.

As a previous stage to the development of a BDFIM prototype with new rotor configurations in future studies, it could be interesting to implement the test methodology developed in this paper using a finite-element software package. It would be useful in prevalidating the synchronous mode operation of the BDFIM.

\section{REFERENCES}

[1] L. J. Hunt, "A new type of induction motor," J. Inst. Electr. Eng., vol. 38, pp. 648-677, 1907.

[2] F. Creedy, "Some developments in multi-speed cascade induction motors," J. Inst. Electr. Eng., vol. 59, pp. 511-537, 1921.

[3] A. R. W. Broadway and L. Burbridge, "Self-cascade machine: A low speed motor or high frequency bruhsless alternator," Proc. Inst. Electr. Eng., vol. 117, no. 7, pp. 1277-1290, 1970.

[4] R. Li, A. K. Wallace, R. Spée, and Y. Wang, "Two axis model development of cage-rotor brushless doubly-fed machines," IEEE Trans. Energy Convers., vol. EC-6, no. 3, pp. 453-460, Sep. 1991.

[5] R. Li, R. Spée, A. K. Wallace, and G. C. Alexander, "Synchronous drive performance of brushless doubly-fed motors," in Proc. Ind. Appl. Soc. Annu. Meet., Houston, TX, 1992, vol. 1, pp. 631-638.
[6] C. S. Brune, R. Spée, and A. K. Wallace, "Experimental evaluation of a variable-speed, doubly-fed wind-power generation system," IEEE Trans. Ind. Appl., vol. 30, no. 3, pp. 774-780, May/Jun. 1994.

[7] C. Veganzones, F. Blázquez, and D. Ramírez, "Guidelines for the design and control of electrical generator systems for new grid conneted wind turbine generators," in Proc. IEEE 28th Annu. Conf. Ind. Electron. Soc. (IECON 2002), pp. 3317-3325.

[8] Y. Liao, "Design of a brushless doubly-fed induction motor for adjustable speed drive applications," in Proc. 31st Ind, Appl. Soc. (IAS 1996) Annu. Meet. Ind. Appl. Conf., San Diego, CA, vol. 2, pp. 850-855.

[9] S. Willianson, A. C. Ferreira, and A. K. Wallace, "Generalised theory of brushless double fed machine. Part 1: Analysis," Proc. Inst. Electr. Eng. Electr. Power Appl., vol. 144, no. 2, pp. 111-122, Mar. 1997.

[10] S. Willianson and A. C. Ferreira, "Generalised theory of brushless double fed machine. Part 2: Model verification and performance," Proc. Inst. Electr. Eng. Electr. Power Appl, vol. 144, no. 2, pp. 123-129, Mar. 1997.

[11] E. Wiedenbrug, M. S. Boger, A. K. Wallace, and D. Patterson, "Electromagnetic mechanism of synchronous operation of the brushless doublyfed machine," in Proc. Ind. Appl. Conf., 1995, Orlando, FL, vol. 1, pp. 774780.

[12] F. Wang, F. Zhang, and L. Xu, "Parameter and performance comparison of doubly-fed brushless machine with cage and reluctance rotors," in Proc. Ind. Appl. Conf., 2000, Rome, Italy, vol. 1, pp. 539-544.

[13] A. L. Mohamadein, M. M. Ahmed, and M. M. El-Daba, "Mixed-pole reluctance machine with ring-coils on rotor poles (a novel rotor version)," in Proc. IEEE Int. Electr. Mach. Drives Conf., (IEMDC 2001), Cambridge, MA, pp. 705-710.

[14] F. Blázquez "Desarrollo de un nuevo generador asíncrono de doble bobinado en el estator para grandes aerogeneradores de velocidad variable," $\mathrm{Ph}$.D. dissertation, Univ. Politéc, Madrid, Spain, Apr. 2004.

[15] F. Blázquez, C. Veganzones, D. Ramírez, J. R. Arribas, and M. Lafoz, "Brushless doubly-fed asynchronous generator for variable speed wind generation systems," presented at the Int. Conf. Electr. Mach. (ICEM 2002), Brujas, Belgium, Aug.

[16] S. Williamson and M. S. Boger, "Impact of inter-bar currents on the performance of the brushless doubly-fed motor," in Proc. 32nd Ind. Appl. Soc. (IAS 1997) Annu. Meet. Ind. Appl. Conf., New Orleans, LA, vol. 1, pp. $188-195$.

F. Blázquez (M’07) was born in Toledo, Spain, on April 9, 1972. He received the Dipl. degree in industrial engineering and the Ph.D. degree in electrical engineering from the Universidad Politécnica de Madrid, Madrid, Spain, in 1997 and 2004, respectively.

Since 1999, he is a Professor in the Electrical Engineering Department, Universidad Politécnica de Madrid. His current research interests include electrical machine design and wind power generation. 
C. Veganzones teceived the Dipl. degree in industrial engineering from the Polytechnic University of Cataluña. Barcelona, Spain. in 1982, and the Ph.D. degree in electrical engineeting from the Universidad Politécnica de Madrid. Madrid, Spain, in 1990

$\mathrm{He}$ is currently a Professor in the Electrical Engineering Department, Universidad Politécnica de Madrid. His current research interests include wind energy systems and control drives.

D. Ramírez (M'07) was born in Palencia. Spain. on November 15. 1966. He recejved the Dipl. degtee in electrotic engineering and the Ph.D. degree in industrial engineering from the Universidad Politécnica de Madrid, Madrid, Spain, in 1997 and 2003, respectively.

Since 1997, he is a Professor in the Electrical Engineering Department. Utniversidad Politécnica de Madrid. His current research interests include digita] signal processors, electrical drives, and power electronics.
C. Platero was born in Madrid, Spain. on Aptil 17, 1972. He received the Dipl. degree in industrial engineering from the Universidad Politécnica de Madrid, Madrid, in 1996.

He was with the Power Generation Department of ENDESA, an electric power company. Since 2004, he is an Assistant Professor in the Electrical Engineering Department. Universidad Politécnica de Madrid. His cultent research interests include electrical machine design and power generation. 